\title{
Aplicação do método de caminhamento elétrico na correlação de fraturamentos
}

Coppi, D. A*., UNIPAMPA, Caprara, B.B., UNIPAMPA, Gomes, C. H, UNIPAMPA

Copyright 2018, SBGf - Sociedade Brasileira de Geofísica

Este texto foi preparado para a apresentação no VIII Simpósio Brasileiro de Geofísica, Salinópolis, 18 a 20 de setembro de 2018. Seu conteúdo foi revisado pelo Comitê Técnico do VIII SimBGf, mas não necessariamente representa a opinião da SBGf ou de seus associados. É proibida a reprodução total ou parcial deste material para propósitos comerciais sem prévia autorização da SBGf.

\begin{abstract}
Geophysical methods are a means of analyzing geological structures used for areas where mapping is not possible on the surface. Among these methods, the study of horizontal and vertical discontinuities based on the electrical characteristics of the soil was used, being the one chosen for an area analyzed in this paper, being this one a sandstone with different degrees of alteration. This paper is presented to the application of the electric sliding technique, with the purpose of doing the following: through the dipole-dipole arrangement in an area of the Minas do Camaquã - RS and shows an electrical resistance along two profiles. Based on the calculation and analysis of the obtained data, it is possible to conclude the effectiveness of the method for this type of geology and to differentiate the degree of fracturing in saprolites.
\end{abstract}

\section{Resumo}

Os métodos geofísicos são um importante meio de análise de estruturas geológicas usados para áreas quando o mapeamento não é possível em superfície. Dentre estes métodos. Dentre estes métodos o da resistividade elétrica, usado no estudo de descontinuidades horizontais e verticais com base nas propriedades elétricas do solo, foi o escolhido para a área analisada neste trabalho, sendo este um arenito com diferentes graus de alteração. Este trabalho apresenta à aplicação da técnica de caminhamento elétrico, que investiga variações laterais, por meio do arranjo dipolodipolo em uma área das Minas do Camaquã - RS e nos mostra a resistividade elétrica ao longo de dois perfis. Com base no processamento e análise dos dados obtidos foi possível concluir a efetividade do método para este tipo de geologia e diferenciar o grau de fraturamento nos saprolitos.

\section{Introdução}

Estudos geológicos com foco na análise e caracterização estratigráfica nos fornece informações importantes em estudos de rochas sedimentares. No entanto, a avaliação de estruturas e descontinuidades por meio de mapeamento de superfície apresenta algumas limitações em decorrência da cobertura de solo e densidade vegetal. Como meio de facilitar esta avaliação se utilizam métodos geofísicos, dentre os métodos existentes o método de eletrorresistividade oferece técnicas de levantamento que podem ser divididos entre sondagem elétrica vertical e caminhamento elétrico.

Este método se baseia no estudo do potencial elétrico tanto dos campos naturais quanto dos campos artificiais, através das medições de potencial elétrico na superfície pode-se determinar, no subsolo, a existência de corpos minerais e reconhecer estruturas geológicas (TELFORD et al, 1990).

Neste estudo, pretende-se obter, por meio da análise da estrutura em subsuperfície, informações que possam contribuir para o mapeamento do grau de fraturamento do saprolito encontrado na região das Minas do Camaquã - RS através do método da eletrorresistividade por meio do caminhamento elétrico.

A área de estudo (Figura 1) situa-se no município de Caçapava do Sul, localidade de Minas do Camaquã a cerca de $350 \mathrm{~km}$ da capital Porto Alegre, localizada na porção central do Escudo Sul-riograndense.

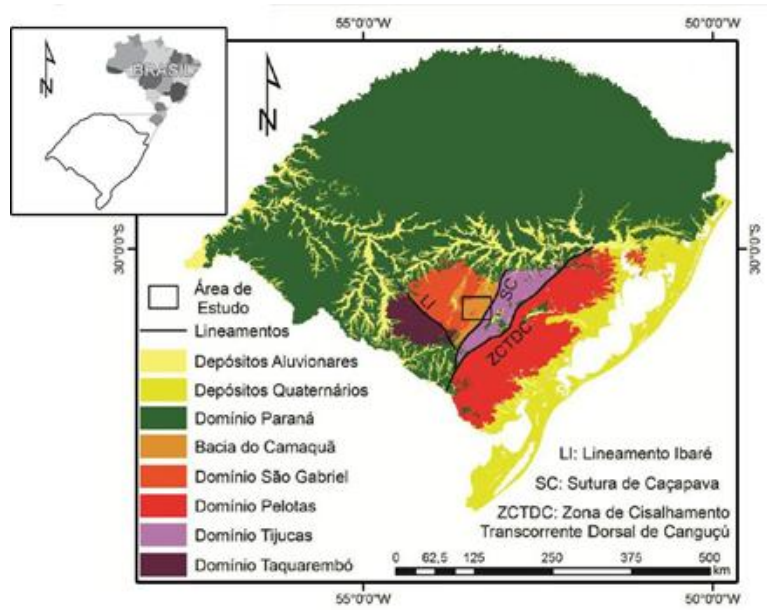

Figura 1 - mapa tectônico do Rio Grande do Sul com destaque para a localização da área de estudo (Tavares et al 2014)

As Minas do Camaquã estão situadas no centro da bacia intracratônica do Camaquã, que tem direção NE-SW e é limitada por grandes falhas de expressão regional. A Bacia do Camaquã é preenchida por sedimentos siliciclásticos intercalados com rochas vulcânicas. $\mathrm{Na}$ área de estudo evidencia-se a Formação Arroio dos Nobres de Tessari \& Picada (1996). Esta formação é subdividida em dois Membros Mangueirão e Vargas, 
sendo o contato entre eles gradual, contendo arenitos e conglomerados de granulação diversa.

\section{Metodologia}

As etapas adotadas para este estudo compreendem a aquisição, o processamento, a análise dos dados e a integração geofísica/geológica da área.

Para a aquisição dos dados elétricos foram medidas duas linhas: 1 e 2. A linha 1 com comprimento de 360 metros e a linha 2 com comprimento de 240 metros, ambas as linhas com espaçamento de 5 metros entre os eletrodos e direção N-S. O equipamento utilizado foi o Syscal-Pro de modelo Switch 72 da IRIS da Universidade Federal do Pampa.

A principio, os dados foram filtrados com a remoção de pontos que apresentavam erros de medidas e a partir da nova base de dados com valores de resistividade filtrados, os dados foram processados com um espaçamento de $2,5 \mathrm{~m}$, no intuito de obter uma melhor resolução dos resultados. O processamento se deu com o uso da técnica de inversão por meio do método dos mínimos quadrados que consiste em encontrar o melhor ajuste para um conjunto de dados tentando minimizar a soma dos quadrados das diferenças entre 0 valor estimado. Para o georeferenciamento das imagens de satélite e confecção dos demais mapas foi utilizado o software livre QGIS 2.18.4. A análise dos dados se deu a partir dos resultados obtidos que mostram a inversão dos dados em um modelo padronizado afim de facilitar esta análise. A partir disso foi gerado um mapa lito-geofísico correlacionando os valores obtidos através do levantamento geofísico às litologias do local.

\section{Resultados e discussões}

Os resultados do processamento são apresentados na forma de modelos de inversão (Figura 2).

Para a linha 1 (Figura 2A), os valores mais altos de resistividade, que variam de 182 ohms a 661 ohms vistos na primeira sessão do mapa de inversão, de $0 \mathrm{~m}$ a $5 \mathrm{~m}$ de profundidade, são correlacionáveis ao solo seco e certa densidade vegetal (observado na aquisição dos dados). Assim, em presença de água pode haver diminuição dos valores de resistividade. Já nas áreas de maior valor de resistividade foi observado, em campo, à presença de rocha sã aflorante, podendo ser responsável pelo valor de resistividade alta. Ao mesmo tempo em que, a presença de solo seco faz com que o valor de resistividade aumente devido à falta de umidade desse solo, auxiliando no fluxo de corrente. Para a segunda sessão do mapa de inversão, de 5 a $35 \mathrm{~m}$ de profundidade, é possível observar uma camada pouco resistiva, variando de 118 ohms a 182 ohms, correlacionada a uma zona de alto grau de faturamento. O que permite, neste caso, possivelmente, a percolação de fluidos na área. Nota-se a presença de uma descontinuidade geoelétrica com valores de resistividade baixa na ordem de 50 ohms na porção sul do levantamento, localizada a uma profundidade de aproximadamente 25 a $40 \mathrm{~m}$. Tendo em visto que a área de estudo e a região apresentam falhas no sentido NESW, pode-se inferir que esta descontinuidade geoelétria se refere a uma dessas estruturas. Também é possível observar a presença de corpos com valores de resistividade na ordem de 200 ohms indicando áreas com menores valores de fraturamento do saprolito. A última sessão, que varia de 35 a $72 \mathrm{~m}$ de profundidade, possui valores de resistividade na ordem de 279 ohms e indica um corpo rochoso com grau médio de faturamento. Neste caso, é possível correlacionar a rocha sã na parte sul do levantamento, com uma resistividade alta e com valores superiores a 1016 ohms. Os valores de 1016 a 279 ohms, nesta seção foram, então, interpretados como a superfície de intemperismo dessa rocha, com valores que variam de 1016 a 279. Outra descontinuidade geoelétrica pode ser visualizada na última sessão, com profundidade de $60 \mathrm{~m}$, aproximadamente, na porção central do levantamento e com valores de resistividade na ordem de 118 ohns, indicando outra zona de falhamento.

Para a linha 2 (Figura 2B) também é possível observar valores altos de resistividades na ordem de 430 a 715 ohms de 0 a $4,5 \mathrm{~m}$ de profundidade, aproximadamente. Também correlacionado ao solo seco observado in loco no dia do levantamento. A segunda sessão, que varia de 4,5 a $50 \mathrm{~m}$, apresenta valores de resistividade médios, na ordem de 279 ohms, indicando uma zona não muito fraturada do saprolito, visto que não possui muito espaço entre fratura para a percolação de fluidos.

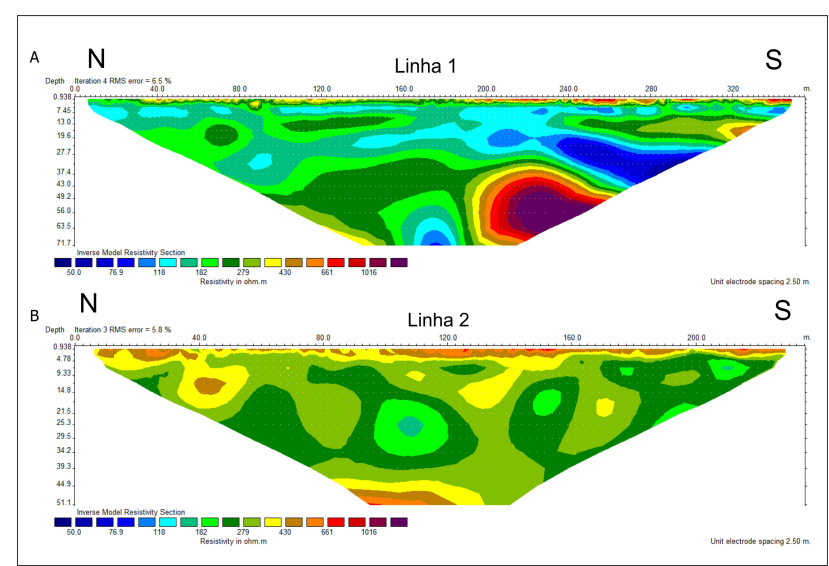

Figura 2 - modelo de inversão para os valores de resistividade obtidos.

A partir da análise feita nos modelos de inversão foi possível gerar os mapas lito-geofísicos para as linhas 1 e 2 (Figura 3), que demostram a distribuição das diferentes de litologias com base no grau de faturamento do saprolito. 


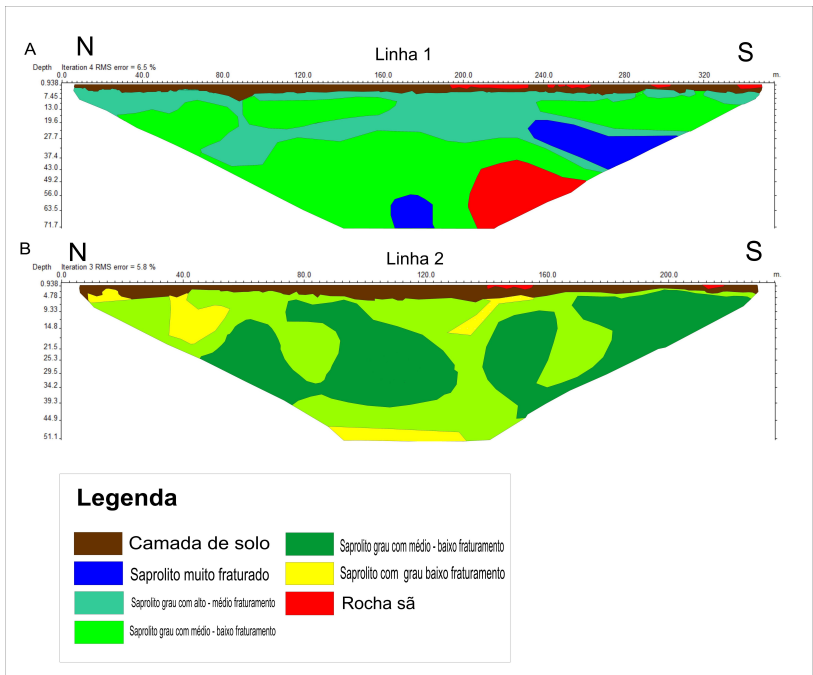

Figura 3- mapa lito-geofísicos das linhas 1 e 2

\section{Conclusão}

Após a interpretação dos dados obtidos com o método de eletrorresistividade através de caminhamento elétrico foi possível concluir que as alternâncias de resistividade podem estar associadas a variação de fraturamento encontradas na área, visto que rochas porosas, ou no caso, mais fraturadas proporcionam maior percolação de fluidos, tais como a água, que pode resultar na diminuição da resistividade da rocha. A partir dos modelos gerados e dos mapas geológicos é possível observar que as regiões com menor resistividade são relacionadas ao saprolito em subsuperfície, que apresenta maior grau de faturamento. Assim, uma maior capacidade de percolação de fluidos em seu interior, possibilitando um meio para a corrente elétrica fluir pela rocha. Diferente das regiões onde a presença de rocha sã aflorando na superfície vista nos dois mapas e a região de maior resistividade vista no mapa da linha 1 e 2, gera um meio de resistividade muito maior, possivelmente devido à falta de fraturas.

\section{Agradecimentos}

Os autores agradecem ao Geól. S.B. Lago e a Nexa Resources por permitir o levantamento geofísico na área de estudo.

\section{Referências}

Bettencourt J. S., 1972. A Mina do Camaquã, Rio Grande do Sul. 1972. 196 f. Tese (Doutorado em Geociências) - Instituto de Geociências, Universidade de São Paulo, São Paulo.
Borba, A. W., at al, 2014. Evolução Tectono-Estratigráfica e Paleoclimática da Formação Maricá (Escudo-Sul-RioGrandense, Brasil): um Exercício de Geologia Histórica e Análise Integrada de uma Bacia Sedimentar Neoproterozóica. Revista Pesquisa em Geociências, Porto Alegre, vol. 2, p. 57- 74.

Calachibete, C., 2016. Caracterização Lito-Geofísica por Métodos Geoelétricos na Região da Baixada Cuiabana Trend Pirizal - Bento Gomes. 2016. 91 f. Dissertação (Mestrado em Geociências) - Instituto de Geociências, Universidade de Brasília, Distrito Federal.

Paim, P. S. G., 2013. Minas do Camaquã, RS: Marco da história da mineração de cobre no Brasil. SIGEP, Porto Alegre, vol. 64, p. 501-510.

Telford, M. W. Geldart, P. L., Sheriff, E. R., 1990. Applied Geophysics. Segunda edição, editora Cambridge, NY. 